\title{
The approach of United States school terms means sleep schedule changes are needed
}

\section{Commentary}

The fun-filled days of summer are nearing a close with school doors opening very soon. It is common for the unstructured time of the summer to give way to late bedtimes, sleeping in on weekday mornings and napping. The elementary/middle school student corresponds to age 6-12years old. The National Sleep Foundation has published survey studies on their website including the most common sleep duration times by age. For the elementary education/middle school aged child, $9-11$ hours of sleep is typical. With the summer unstructured time, it is likely that some changes the student's sleep may be occurring. For many students, it may be that the summer time provided a means to catch up on the chronic school-year deprivation ${ }^{1}$. With the median school time as $8 \mathrm{am}$, the return to a deprived sleep may prevail. A small percent of schools, largely in the northeast, have advanced their school start times. In the measurements of sleep quality in these schools with advanced school start time, improvements have been stated.

A need for a later school start times prevails with only a minority of schools addressing this recommendation. The component along with the summer days of catch up, longer sleep interval times is closing to an end., ${ }^{1,2}$ While larger scale factors such as the sociopolitical policy generation and compliance of late school start times prevails, other adjustments for the student sleeper are needed. Findings for the administration of the child's sleep habit questionnaire indicated that $43 \%$ of elementary school children and $29 \%$ of middle school children reported trouble sleeping . ${ }^{2}$ Further, bedtime resistance, nighttime awakening and sleep onset delay were more common with elementary school children as compared to middle school aged children in their study. Middle school children participants reported adhering to sleep hygiene practices more so than elementary school children. ${ }^{2}$ These findings indicate the need for Sleep Specialists to design interventions specific to these two groups. In the recent past, the ages had been grouped together, but findings suggest a need to specify the two age groupings. Further, the middle school aged student at the upper age end, is approaching adolescence and for some in that category, the advanced sleep start time characteristics may be relevant. ${ }^{2,3,4}$

Three lines of intervention are needed. Sleep specialists could provide workshops about elementary aged and middle school aged sleep needs. Second, interventions in terms of Parent training, particularly for the elementary aged student sleep where bedtime resistance is more prevalent would be helpful. ${ }^{1,2,3,4}$ School based

\author{
Volume 2 Issue 4 - 2018 \\ Kathy Sexton-Radek \\ Department of Psychology, University Elmhurst College, USA
}

Correspondence: Kathy Sexton-Radek, Department of Psychology, University Elmhurst College, 190 Prospect Avenue, Elmhurst, IL, 60I26, USA, Tel 6306 I735 87, Email ksrsleep@aol.com

Received: July 29, 2018 | Published: September 12, 2018

interventions in health courses or by school counselors that start on the sleep hygiene habits and sleep scheduling is likely to be effective. Regardless of the line of intervention, while all three would be optimal, some intervention is essential and the timing for intervention is now. At the time of this publication, it is likely that some $2-3$ weeks remain of the student sleepers summer schedule. The guidance to better sleep habits for school days will provide the student sleeper with more academic satisfaction and well-being.

\section{Acknowledgements}

None

\section{Conflict of interest}

The author declares there is no conflict of interest.

\section{References}

1. Lahey J. Students aren't getting enough sleep---school starts too early. Editors. Washington D.C: The Atlantic: Hayley Romer; 2014.

2. Surani S, Sean Hesselbacher, Saherish Surani et al. Sleep Habits of Elementary and Middle School Children in South Texas. Sleep Disorders. 2015; 9 p.

3. Carskadon MA, Wolfson AR, Acebo C, et al. Adolescent sleep patterns, circadian timing and sleepiness at a transition to early school days. Sleep. 1998;21(8):871-881.

4. Owens JA, Spirito A, McGuinn M. The Children's Sleep Habits Questionnaire (CSHQ): psychometric properties of a survey instrument for school-aged children. Sleep. 2000;23(8):1043-1051. 